\title{
Authoritarian Environmentalism Undermined? Local Leaders' Time Horizons and Environmental Policy Implementation in China
}

\author{
Sarah Eaton ${ }^{*}$ and Genia Kostka ${ }^{\dagger}$
}

\begin{abstract}
China's national leaders see restructuring and diversification away from resource-based, energy intensive industries as central goals in the coming years. On the basis of extensive fieldwork in China between 2010 and 2012, we suggest that the high turnover of leading cadres at the local level may hinder state-led greening growth initiatives. Frequent cadre turnover is intended primarily to keep local Party secretaries and mayors on the move in order to promote the implementation of central directives. While rotation does seem to aid implementation by reducing coordination problems, there are also significant downsides to local leaders changing office every three to four years. Officials with short time horizons are likely to choose the path of least resistance in selecting quick, low-quality approaches to the implementation of environmental policies. We conclude that the perverse effects of local officials' short time horizons give reason to doubt the more optimistic claims about the advantages of China's model of environmental authoritarianism.
\end{abstract}

Keywords: authoritarian environmentalism; cadre rotation; environmental policy implementation; China; leadership; time horizons

In light of wealthy democracies' generally lacklustre responses to global environmental crises, the question of whether authoritarian regimes might make better environmental managers has attracted attention in recent years. ${ }^{1}$ In the face of a rapidly unfolding climate change crisis, advanced democracies have often seemed flat-footed - paralysed by interminable negotiations at the international level and the ceaseless pressure of lobby groups and high-consuming voters at

* The University of Oxford Centre for China Studies. Email: eatonsarahb@gmail.com (corresponding author).

$\dagger$ The Frankfurt School of Finance and Management. Email: geniakostka@gmail.com.

1 See e.g. Josephson 2004; Beeson 2010. 
home. In contrast, authoritarian regimes are seen as potentially more nimble and capable. The combination of a higher degree of state autonomy and a society habituated to the exercise of coercive power may confer certain advantages on "eco-elites" in non-democracies. ${ }^{2}$ China's rapid advances in environmental protection have made it a focal point of debate over the relative merits of democratic and authoritarian environmentalism. ${ }^{3}$ Proponents of China's approach admire its state leaders' ability to compel businesses and citizens to comply with stringent environmental regulations. Chinese authoritarians' toolkits contain many more, and sharper, implements to elicit such compliance. For instance, many energy-inefficient companies that failed to comply with demanding energy efficiency regulations have found their electricity and water supply summarily cut off by local governments. In contrast to politicians in democracies who, heavily constrained by electoral cycles, weigh the cost of environmental protection in terms of lost votes, authoritarian leaders are potentially better environmental stewards, so the story goes, as they are comparatively insulated from societal pressure and can take the long view on environmental issues.

This article casts a critical eye on optimistic claims about China's authoritarian advantage. While national leaders in Beijing have committed to addressing China's environmental crisis, local leaders, who bear responsibility for interpreting and carrying out environmental policies, typically have very short time horizons and are not strongly incentivized to take on the difficult business of changing lanes from a growth-at-any-cost model to a resource-efficient and sustainable path. ${ }^{4}$ While there are some advantages of cadre rotation for environmental policy implementation, our research highlights the negative and unintended consequences of a system that keeps local officials on the move. The immense pressure of a short term in office, during which time leaders must produce results to be considered for promotion, incentivizes local leaders to select highly visible projects that deliver outcomes during their own tenure periods, while long-term complex initiatives are often sidelined.

The findings presented here are based on extensive fieldwork carried out between 2010 and 2012. During the first phase of research in 2010 and 2011, covering a period of five months, the authors studied variation in cadre turnover and its impact on environmental policy implementation in five municipalities and 11 counties in Shanxi province. Shanxi is an appropriate choice since leaders' efforts

2 Shearman and Smith 2007.

3 Gilley 2012.

4 At the national level, environmental protection and resource and energy security have taken a place on the core political agenda. China's two most recent national five-year plans, the 11th (2006-2010) and 12th (2011-2015), outline Beijing's ambitious vision for moving towards a more sustainable, environmentally-friendly growth path. The 11th Five-Year Plan identified conservation, efficient use of resources and economic transformation in the interests of sustainable development as key national policies. The 12th Five-Year Plan has added substance to these concepts by establishing the shift to higher value-added manufacturing, improvement of energy and resource conservation and expansion of the service sector as key goals. "Hard," meaning restricted (yueshuxing), and "soft" or expected (yuqixing) targets have been incorporated in the 11th and 12th Five-Year Plans as incentives for local cadres. 
to diversify away from heavy reliance on the coal industry and embark on a "green rise" (lüse jueqi 绿色崛起) offer critical insights into the opportunities and challenges on the road ahead for the country as a whole. The empirical section also draws on two months of fieldwork on the same topic in Hunan and Shandong provinces in 2012. In total, the authors conducted 89 interviews (45 in Shanxi, 26 in Hunan and 18 in Shandong). The majority of interviews were held with leading officials in the Chinese Communist Party (CCP) Organization Department, environmental protection bureaus (EPB), Development and Reform Commission (DRC) and Economic Commission. Interviews were also conducted with industrial enterprise managers involved in economic transformation programmes. Findings are also based on government reports provided in interviews, as well as local gazetteers and media accounts.

\section{The Rationale and Policy Impact of High Cadre Turnover}

China's local officials gather no moss. Most government leadership positions at county and municipal levels are for a prescribed term of five years, yet only a small minority of leading officials actually serve out these terms in full. The majority move on to the next position within three to four years. In the context of China's complex central-local relations, central authorities have long viewed the periodic rotation of local officials as a tool to enhance the control and monitoring of local officials. While these comprise the core goals behind the tangle of regulations and informal practices that govern official post-switching, a number of auxiliary aims related to cadre training, diffusion of local policy innovations and bridging administrative gaps have been woven into the system in recent years. Despite the evident importance which China's leaders attach to this system, surprisingly little research has been done on whether high cadre turnover actually delivers its intended benefits.

Available data suggest that the two pillars of local leadership groups (lingdao banzi 领导班子) - Party secretaries and mayors - are typically whisked off to a new locale well before the recommended five-year term for civil servants and Party cadres in leadership positions. ${ }^{5}$ Cadre turnover takes the form of promotion, lateral rotation and, much less frequently, demotion. ${ }^{6}$ Short-term appointments are also common in China's cadre management system, whereby officials are temporarily stationed in a particular department or locality for a short period (such cadres are known as guazhi 挂职). Data on 898 former

5 The five-year tenure limit is, in reality, a firm recommendation rather than a hard and fast rule. A 1999 CCP Organization Department document set ten years as the absolute limit for cadres in leading positions, but rules stating that cadres should change positions at five-year intervals are phrased in the language of "should" (yinggai) rather than "must" (bixu). This flexibility explains why some cadres have tenures longer than five years.

6 The post-switching of leading cadres takes place via two systems, both of which are managed ultimately by the CCP Organization Department. The cadre selection and appointment system (lingdao ganbu xuanba renyong zhidu) handles promotion and demotion decisions for leading cadres, while the cadre rotation system ( $g$ anbu jiaoliu zhidu) applies to cadre flows between positions of equal rank. 
municipal Party secretaries appointed across China between 1993 and 2011 reveal that the average time in office was 3.8 years, with a minimum tenure of 0.2 years and a maximum of 12.8 years $;^{7} 23$ per cent of municipal Party secretaries spent two years or less in their positions, while only 25 per cent stayed for five years or more. Previous work has found that mayors at county and municipal levels also tend to serve between three and four years before moving on to their next assignment. ${ }^{8}$ Beyond the leadership group, departmental heads with a key role in environmental policy implementation also rotate, on average, every four years. ${ }^{9}$

Evidence suggests that the trend is towards faster rotation of local officials. There has been a significant drop in average tenure time over the last two decades. While in the 1990s average tenure length was 4.2 years and more than 35 per cent of the 898 municipal Party secretaries surveyed served longer than five years, between 2002 and 2011 average tenure dropped to 3.3 years and less than 14 per cent stayed beyond five years. Landry's analysis of the average tenure times of 2,058 municipal mayors serving between 1990 and 2001 is even more striking as it suggests that tenure times steadily declined from an average of 3.2 years in the 1990 s to 2.5 years by $2001 .^{10}$

\section{Policy origins of high cadre turnover}

This churning of local leaders is largely a legacy of the Deng-era leadership's interest in strengthening the centre's levers of control over the localities. As part of a broad effort to rebuild the cadre management system in the early reform period after 1978, the central leadership strove to place limits on local cadres' incentives and opportunities to engage in localism by keeping them away from their home turf and on the move. Central leaders sought, first, to revive the imperial Rule of Avoidance (huibi zhidu 回避制度), which directs cadres away from holding office in their places of origin. References to the Rule of Avoidance began to reappear in policy documents after 1978, and the terms have been gradually clarified and hardened over time. ${ }^{11}$ The Central Organization Department's 1999 "Interim measures for the rotation of Party and government leading cadres" 12 significantly broadened the scope of avoidance by stipulating that leading cadres in key Party and government positions should not serve in their ancestral homes, places of birth or in the places where they grew

7 The source is the authors' database of biographic information for 898 municipal Party secretaries and 124 provincial departmental heads.

8 Seckington 2007, 19; Mei 2009, 102.

9 For instance, the average time served as head of a provincial DRC, the head of a provincial EPB and the head of a provincial construction bureau was 3.56 years, 4.00 years and 4.60 years, respectively (Kostka 2013). As discussed below, the frequent rotation of directors in functional departments can be disruptive to local development planning. However, while leading cadres are frequently rotated, ordinary cadres are not, meaning that standard administrative tasks will continue despite leadership changes.

10 Landry 2008, 90.

11 Mei 2009, 49.

12 Communist Party of China Central Committee Organization Department. 1999. "Dangzheng lingdao ganbu jiaoliu gongzuo zanxing guiding." 
up (although exceptions may be granted in autonomous regions for ethnic minorities). To combat problems of nepotism, the policy also stated that leading cadres must not be married to nor have any direct blood relations with other cadres working in the same organization.

The central control rationale also informed the leadership's calls for restoring the practice of periodic leadership rotation on the principle that "flowing water does not get stale, a door hinge is never worm-eaten" (liushui bu fu, hushu bu $d u$ 流水不腐, 户枢不蛽). Prior to the onset of the Cultural Revolution, there existed an official rotation system that mandated the exchange of senior cadres in central and provincial Party and government organs, as well as leading cadres in municipal and county levels. ${ }^{13}$ Previous work has argued that, after 1978, reviving the rotation system was a key move in the centre's largely successful efforts to enhance its control and monitoring of local agents. ${ }^{14}$ The control logic is that a leading cadre stationed in a post for no longer than five years is less likely, all else being equal, to side with local interests against the centre's demands than a leader who has long-standing ties to the area. Frequent cadre turnover is thought to enhance monitoring, since each changing of the guard represents an opportunity for the new leader to provide upper levels with inside information on the predecessor's reign. ${ }^{15}$

While control and monitoring constitute the core aims of the rotation system, relevant policy documents now more often link cadre circulation to the broader mandate of rejuvenating the cadre ranks and strengthening the state's leadership capacity, as emphasized in Deng's "four transformations" (sihua 四化) reforms. This emphasis on frequent post-switching as a method of cadre training is evident in central and local policy documents, as well as in interviews with active and retired officials. The first major policy document on cadre rotation, the Central Organization Department's 1990 "Decision on the implementation of the exchange system of Party and government leading cadres," 16 characterizes the main objectives of rotation in terms of cadre development and training, as well as improving their overall "quality" (suzhi 素质). Of the various ways in which rotation has been promoted in the name of cadre training, perhaps the most significant practice is the temporary posting of cadres to gain experience (guazhi duanlian 挂职锻炼).

Over time, policy documents and specific rotation programmes have increasingly framed rotation as a means of reducing regional disparities and bridging administrative gaps. Cadre rotation has come to be seen as a potential source of assistance to less developed regions. The Central Organization Department's 2000 document, "Outline for deepening cadre management reform," calls for greater "guidance on cadre exchange to difficult regions and difficult posts"

16 Communist Party of China Central Committee Organization Department. 1999. "Guanyu shixing dang he guojia jiguan lingdao ganbu jiaoliu zhidu de jueding." 
(yindao ganbu xiang jianku diqu he jianku gangwei jiaoliu 引导干部向艰苦地区和 艰苦岗位交流). ${ }^{17}$ To that end, the policy advocates the intensification of eastwest cadre rotation schemes in support of the "open up the west" strategy (xibu dakaifa zhanlüe 西部大开发战略) and calls for cadres from central government institutions and economically-developed eastern provinces to be temporarily posted to western regions. Recent rotation schemes also increasingly envisage cadre exchange as a means of bridging administrative hierarchies and institutional gulfs. For example, the 2006 Civil Servant Law states that leaders at and below provincial rank should implement cross-regional, cross-department lateral transfers (zhuanren 转任). Civil servants can be sent to lower or upper-level authorities, state-owned enterprises (SOEs) or service organizations for short-term training.

In sum, in addition to the core goal of monitoring and controlling local officials, numerous other supplementary aims of cadre rotation have been added over the years. Cadre circulation is increasingly also seen as a way of improving policy implementation through cadre training, the diffusion of policy innovation, and bridging cleavages between departments, administrative hierarchies and regions. However, there is scant research on how cadre rotation schemes affect policy implementation processes and whether they actually deliver their intended benefits.

\section{The significance of cadre rotation for policy implementation}

The length of term served by local officials is not the only factor relevant to policy implementation. In China, as elsewhere, policy implementation is a complex process in which the dispositions and behaviour of local leaders constitute just one piece of the puzzle; however, compared to their counterparts in most other countries, powerful local leaders in China's "decentralized authoritarian" system make up a considerably larger piece of the implementation puzzle. ${ }^{18}$ It is for this reason that we characterize high cadre turnover as an issue of considerable significance for implementation processes and outcomes.

Although the comparative public policy implementation literature is based primarily on examples drawn from democratic, federalist systems, it is useful in providing a broad outline of the factors relevant to China. Sabatier and Mazmanian's classic work groups a total of 17 variables bearing on policy implementation into three categories: "tractability of the problem;" "ability of statute to structure implementation;" and "non-statutory variables affecting implementation."19 Lester and Bowman's statistical test of the Sabatier-Mazmanian framework found that some of these variables had more reach than others in

17 Communist Party of China Central Committee Organization Department. 2000. "Shenhua ganbu renshi zhidu gaige gangyao."

18 Landry 2008.

19 Sabatier and Mazmanian 1980. 
explaining a pattern of state-level variation in implementation of the American Resource Conservation and Recovery Act (1976). ${ }^{20}$ Among the "tractability" variables, they found that the difficulties of measuring and monitoring technically complex issues, as well as a high degree of economic importance in the target group, made implementation less likely. In matters of organizational structure ("statutory" variables), they found partial support for hypotheses positing that bureaucratic fragmentation, the placement of implementation responsibility with an "unsympathetic" agency, and state leaders' ambivalence over policy goals weakened implementation. Of particular relevance to this article, Lester and Bowman found support for two "non-statutory" hypotheses related to political leadership: "the greater the support of sovereigns, the more likely is implementation," and "the greater the commitment and leadership skills of implementing officials, the more likely is implementation." ${ }^{21}$ Despite the obvious differences between the American and Chinese systems, many of the factors identified here are relevant to China. The pathologies of fragmented bureaucracy, difficulties in monitoring less readily measurable complex environmental targets, and official foot-dragging stemming from environment versus growth trade-offs, are all problems familiar to scholars of Chinese environmental politics.

One aspect of the Chinese political system that is perhaps not so easily accommodated by the comparative literature on implementation is the expansive role and broad powers of local leaders in the environmental policy implementation process. Policies formulated at the central level generally articulate very broad aspirations, the interpretation and implementation of which are left to the discretion of local authorities. In this process, Party secretaries and mayors in the local leadership group wield significant authority and influence over almost all major decisions in a locality as they formulate interpretations of national directives, establish a hierarchy of policy priorities and oversee the implementation process. Most important matters, particularly economic and financial affairs, are decided by the leadership group of a locality (either at the municipal or county level). Within the leadership group, Party secretaries usually hold the pre-eminent position and are seen as the first hand (yi ba shou 一把手), while mayors are, ordinarily, the second hand (er ba shou 二把手) and subordinate to the Party secretaries.

The centre's typically loosely-worded environmental directives, coupled with the broad-ranging powers of the local leadership group, and in particular the Party secretary, give local leaders substantial room for manoeuvre in the implementation of directives from on high. Allowing local leaders such significant flexibility to interpret central directives is seen as necessary in a country as vast and diverse as China. The system is also designed to elicit creative local experimentation, the most successful examples of which are designated as models to be promoted nationwide. ${ }^{22}$ Of course, flexibility has its price. Such room 
for manoeuvre, combined with a governance system that lacks thorough checks and balances, can lend local leaders the opportunity to shirk on unpopular initiatives and, generally, to engage in the "selective" implementation of directives. $^{23}$

The cadre responsibility and evaluation system is seen as the big stick used by upper-level authorities to ensure implementation compliance from local leaders. It is for this reason that studies of selective policy implementation in China have so often focused on analysis of incentives embedded in the cadre responsibility and evaluation system, especially bonus and promotion prospects. Economic, social and environmental targets are built into this personnel incentive system and used to evaluate and monitor the performance of public officials holding a position in the Party or government.

Yet, as an accountability mechanism, the cadre responsibility and evaluation system is not without its flaws. Presented with a menu of policy goals, ambitious "street-level bureaucrats" tend to apportion their finite energy and resources to those projects which they expect will boost their career prospects. ${ }^{24}$ While the true basis upon which personnel decisions are made remains something of a black box in the study of Chinese politics, we surmise that cadres strive to enhance their chances of promotion through a combination of informal personal relationship-building with decision makers and on-the-job efforts to deliver "political accomplishments" (zhengji 政绩). Political accomplishment projects often take the form of extravagant construction projects which draw resources away from the implementation of more humdrum policies. ${ }^{25}$

Given that local leaders in China wield such considerable powers, establishing the various effects of leaders' brief tenures is, in turn, an aid to our understanding of the complex process of implementing environmental policy. The existing literature has generally viewed cadre rotation in a favourable light. Huang found that local officials with short tenures were more likely to comply with the centre's efforts to curb inflationary investment in periods of austerity. ${ }^{26}$ Edin's analysis of cadre turnover between township and county levels finds that the system strengthens political control and helps to curb localism as it encourages town leaders to identify more with the next administrative level rather than their own local community. ${ }^{27}$

However, theoretical contributions to the field of political economy suggest that leaders in authoritarian systems with short time horizons are an untrustworthy lot. Drawing from the historical example of Chinese warlords in the Republic period, Olson famously argued that "roving" bandits aimed to maximize their plunder (via taxation) before sweeping on to the next locale. The acquisitiveness of "stationary" bandits with no such outside options is, by

23 O'Brien and Li 1999.

24 Ibid.

25 Cai 2004.

26 Huang 1996.

27 Edin 2003, 48. 
contrast, more far-sighted and more moderate: "The rational stationary bandit will take only a part of income in taxes, because he will be able to exact a larger amount of income from his subjects if he leaves them with an incentive to generate income that he can tax." 28 The following section suggests that there are parallels to be found in the behaviour of some of China's short-tenured officials and Olson's roving bandits.

Other studies underscore the significance of leaders' time horizons in determining the level of state intervention in public policy and the provision of public goods, both in democratic and autocratic systems. ${ }^{29}$ Dionne's statistical study of HIV/AIDS initiatives in 15 autocracies and democracies in Africa found that leaders with a short time horizon are less likely to invest in AIDS public health policies as they do not expect to be in power when AIDS problems emerge, while leaders with longer time horizons intervene and invest more heavily in HIV pandemic prevention. ${ }^{30}$ Wright argues that the time horizons of authoritarian leaders shape how foreign aid funds are disbursed. Dictators secure in their rule can take the long view and, in the manner of stationary bandits, have a greater incentive to invest in public goods. Conversely, leaders preoccupied with fighting off political rivals have shorter time horizons and, Wright argues, tend to see foreign aid funds as a resource to be used to ensure their political survival by buying repression and political support, as well as a means of building their personal wealth as insurance against possible regime change. ${ }^{31}$

In sum, the effects of high cadre turnover on policy implementation in China are not well understood. Given the considerable powers of local officials in the process of policy implementation, we would expect their frequent post-switching to be a salient factor in shaping policy outcomes. However, findings in the existing literature point in opposite directions as to the nature of that effect. While cadre rotation is seen by some as enhancing the prospects of local implementation of central directives, the above-cited comparative literature suggests that short time horizons result in rapacious behaviour and underinvestment in public policies and the provision of public goods. According to this line of thought, the short time horizons of local leaders are likely to have significant negative, unintended consequences as local leaders will shirk on the implementation of those central directives which do not deliver significant particularistic benefits or which cannot be realized within their own tenure. Policy areas that are particularly affected by such behaviour are those in which costs are incurred in the short term but benefits appear only in the long term, such as AIDS prevention or environmental policies. This article sheds additional light on the matter by bringing findings from fieldwork in several provinces of China to bear on the 
question of how frequent cadre turnover affects implementation of environmental policies.

\section{Characteristics of environmental policy}

Environmental policies have a number of distinctive characteristics that tend to make implementation difficult. Many environmental policies are characterized by a time lag such that costs are incurred in the short term but benefits only materialize in the long run. Whereas building a waste-water management facility might provide results within three years, the fruits of many policies in the environmental field, for example the reduction of greenhouse gases, are only realized many years, or even decades, hence. Compared to many other policy fields, environmental policies also have the disadvantage that policy outcomes are not always visible and easily measureable. But there is, of course, variation across environmental issues in this regard: whereas reforestation projects produce unambiguous, visible results, the results of carbon intensity reduction are less visible and less readily measurable. Environmental policies also often involve stark trade-offs against economic growth. ${ }^{32}$ For instance, China's recent "green" plans call on local governments to restructure their economies towards a more diversified, greener industrial structure. Local foot-dragging results from leaders' reluctance to impose high costs on local businesses and depress local employment in the short term. In addition, restructuring the economy is a lengthy and uncertain process. A leader's efforts will take years to come to fruition and they cannot be assured that the new cleaner industries receiving investment today will thrive tomorrow. Finally, environmental policy implementation is frequently hampered by organizational challenges. Many environmental policies touch on diverse issue fields that require the cooperation of different functional departments. Also, the units of environmental protection such as lakes, rivers or wetlands are complete ecosystems that span discrete administrative units. In these conditions, varying levels of economic development, in particular, tend to inhibit cooperation on environmental protection across localities.

\section{Effects of Cadre Rotation on Environmental Policy Implementation in China}

While the political rationale behind high cadre turnover is clear, there has, to date, been little empirical work carried out on the effects of the system on environmental policy implementation. Previous work and interviews with current or retired cadres reveal a complex picture showing both pros and cons to cadre rotation schemes. In the following sections, we discuss our findings on the most important advantages and disadvantages of frequent post-shuffling among local cadres. 


\section{Pros of the Cadre Turnover System}

Short leadership cycles can aid the implementation of environmental policies in certain ways. Frequent post-shuffling among local cadres helps to reduce the institutional cleavages and bureaucratic fragmentation that tend to inhibit environmental policy implementation.

\section{Bridging horizontal gaps: improved coordination among departments}

Recent rotation schemes have helped to bridge departmental gulfs, an eternal problem in China's huge and fragmented bureaucracy. Cadres who rotate through departments within their locality are thought to develop a deeper knowledge of the particularistic bureaucratic interests and policy priorities of different local departments. Gaining an understanding of the policy mandates of particular agencies and forging cross-departmental networks can help local leaders identify areas of common interest and aid the formation of formal or informal "green coalitions." Such networks can also be helpful in the process of policy implementation. For example, according to EPB officials working in a county in northern Shanxi, the EPB head's prior work experience in the coal management bureau (mei guan ju 煤管局) brought "additional guanxi 关系 (personal connections) and enterprise knowledge. Our leader understands how to deal with big coalmines and he knows the mine owners very well. His previous experience also helped the EPB to establish a very good working relationship with the coal management bureau." 33 Such coordination between departmental bureaucratic interests is especially important in environmental policy implementation, which often requires more than ten departments to work jointly on a particular issue.

\section{Bridging vertical gaps: transfer of resources, knowledge and policy support}

Many rotation schemes employ cadre exchange also as a means of shortening vertical administrative hierarchies. In 2010, for example, Heilongjiang province rolled out a programme to increase rotation between provincial, municipal and county-level cadres in order to improve information flows downwards and upwards. In its first year, 100 cadres from local levels were posted to provincial offices and the province sent 110 cadres down to local positions. Many EPBs across China have also launched similar rotation schemes across administrative levels. In Wenshan 文山 prefecture in Yunnan, for instance, two thirds of all cadres in the EPB undergo rotation. By exchanging county and municipal EPB cadres for a minimum of a six-month period, the programme intends to smooth environmental policy implementation by enhancing communication across

33 INT10_09092011. To protect the anonymity of interviewees, interview sources are coded throughout this article. Detailed information about interviews and fieldwork is available upon request from the authors. 
administrative levels and improving cadres' knowledge of the upper or lower governments' daily environmental tasks.

Circulating cadres between different administrative levels also channels scarce resources to localities to aid environmental implementation. ${ }^{34} \mathrm{~A}$ government official who had previously worked at the Ministry of Commerce in Beijing explained how his networks in Beijing helped a municipal city win a coveted model environmental city designation:

While working as a vice-mayor in a municipality in Zhejiang, I served as an important link to the central government. Municipal leaders had declared, as one of their five-year plan goals, to obtain the national title of a "model environmental city" (huanbao mofan chengshi 环保模 范城市). They had completed all the paperwork and fulfilled all criteria, but with hundreds of cities applying for the title at the same time, the municipality could have waited a long time for inspection and a final decision. To speed up the process and to ensure that the municipality got the title, I went to Beijing and talked to the Ministry of Environment. I convinced them that comprehensive plans were behind the municipality's application. At the Ministry of Environment, they took me seriously because I previously worked as a mid-level civil servant in the Ministry of Commerce. I was familiar with the procedures and regulations and the Ministry of Environmental "gave me face." In the end, the municipality got the title quickly, which in turn meant fulfilling its five-year objectives plus having access to additional finance. ${ }^{35}$

Fieldwork provided numerous additional examples of how local cadres' personal networks established in previous posts proved critical to attracting investors and securing project funding. Provincial cadres also gain from personal networks linking them to municipal and county leaders. One official working at the Anhui provincial government recalled how "having worked as a vice-mayor made it easier for me to convince leaders from the same municipality to join our provincial pilot programme aimed at restructuring local economies because they trusted me. While working together, communicating with municipal leaders was also much simpler because I was so familiar with the municipality." 36

\section{Bridging regional gaps: dissemination of ideas and information}

Cadre rotation also helps with the dissemination of innovative implementation methods. Leading cadres are frequently posted to a different locality at the same administrative level. ${ }^{37}$ Many localities in China are searching for alternatives to energy-intensive or resource-reliant economic development models and look to seconded leaders for ideas. For example, in 2008, it became clear that Datong 大同, a coal-mining municipality in northern Shanxi, urgently needed to restructure its economy as it was running out of coal. Among different restructuring alternatives, developing the tourism sector was seen to be a feasible

34 INT31_29092011.

35 INT05_08092011.

36 INT141_11022007.

37 For example, of 898 municipal Party secretaries newly appointed during 1993-2011, 14\% of them were already working as municipal Party secretaries in their previous work positions, but in a different locality. 
strategy. Accordingly, provincial leaders appointed a new municipal mayor in 2008, Geng Yanbo 耿彦波, with a proven track record of transforming local economies by building up tourism. ${ }^{38}$ Before being appointed mayor, Geng had successfully restructured other cities in Shanxi by developing tourism, ${ }^{39}$ and according to a staff member in the local leadership group in Datong, Geng's previous successes and experience helped him to persuade other leaders in Datong to support his plan to promote the city's cultural riches in order to attract tourism. ${ }^{40}$

\section{Government-enterprise links: relationships and building alliances}

Job rotations through SOEs and bureaucracies can also aid the enforcement of environmental regulations. Of the 31 provincial EPB heads in 2011, 19 per cent had at some point worked for an SOE. ${ }^{41}$ For example, prior to taking up his government post, the Jiangxi EPB head had forged his career in a provincial chemical SOE, beginning as a factory assistant and eventually rising to become chairman of the board. The cross-sector work experiences of departmental heads improve information flows between state-owned businesses and government sectors and provide government leaders with key management and negotiation skills. For instance, prior to his appointment, the head of the economic commission in Datong municipality had worked as the chief manager of a state-owned enterprise and also in the local state-owned assets supervision and administration commission. His background proved to be very helpful in his current position as "he is very skilled in dealing with SOEs." 42

Such informal linkages between local cadres and SOEs can aid effective environmental management in China. In the context of the immense difficulties presented by regulation and supervision of enterprises, cadres' insider knowledge can reduce information asymmetries between regulator and the regulated. In addition, since formal incentives such as national subsidies for energy or emission savings are often insufficient in themselves to change enterprise behaviour, cadres often need to persuade local enterprises of the benefits of energy and emission savings through unofficial means such as personal appeals, or to furnish side payments outside the formal implementation structure. ${ }^{43}$ During such informal negotiations, government officials with prior work experience at an SOE can draw from their knowledge of enterprises' decision-making processes and internal politics.

38 INT02_01092011.

39 For example, in Lingshi, where Geng was vice-Party secretary and then mayor (1993-2000), one major project was the restoration of the Wang Family Mansion. In Yuci (2000-2006), Geng presided over a large number of construction projects in order to promote tourism (INT37_16072010).

40 INT02_01092011.

41 Kostka 2013.

42 INT22_23092011.

43 Kostka and Hobbs 2012. 


\section{Cons of the Cadre Turnover System}

There are also significant downsides to the rotation system in its current form. As outsiders sent to a post for three or four years, leading cadres face severe time pressures to deliver quick results. Their lack of local knowledge and personal contacts can make it difficult to craft effective implementation plans. In addition, the initiatives developed by local leaders can sometimes reflect leaders' particularist interests in promotion more than the objective needs of the locality.

\section{Roving bandits: self-maximizing and rent-seeking}

Our research suggests that Olson's insights are applicable to China: short tenure cycles do incentivize cadres to prioritize short-term over long-term gains. Such "roving bandit" behaviour was, for example, apparent in Datong municipality prior to the arrival of Mayor Geng Yanbo in 2008. Datong had had a run of unremarkable leaders who stayed an average of 2.9 years and who did little to end the city's heavy dependence on the coal industry. One well-placed city official described how the leaders used their time in Datong primarily as an opportunity for career advancement:

Usually, the previous leaders stayed for a couple of years and then found a chance to get promoted. They used Datong as a springboard. The Party secretary of Datong is a position from which it's easy to get promoted because there are many coal bosses here. That means they can get a lot of bribes and use them to bribe the upper-level government to get promoted. They didn't even need any political achievements to prove themselves ... None of them made any difference. When they left, Datong was the same as when they came. For them, all was good so long as no major problems arose. ${ }^{44}$

Alongside bribes from coal bosses, kickbacks for illegal real estate construction apparently provided further sources of income to buy promotions in the provincial capital city. ${ }^{45}$

Implementation outcomes were disappointing under the leadership of Datong's "roving bandits." These leaders failed to develop any strategies to reduce the heavy environmental toll of the city's coal mining activities, or indeed reduce reliance on the coal industry despite rapidly dwindling supplies of marketable coal. By 2008, national guidelines mandating coal-mining restructuring had not been implemented, the city lacked a strategy for a long-term viable economic growth path, and air and water pollution caused by the predominance of coal in Datong's industrial structure was so severe that Datong was said to wear a "black hat" (hei maozi 黑帽子) for environmental degradation. On the whole, these leaders successfully extracted rents from local industries but did not undertake the painful restructuring so urgently needed by the city. 


\section{Focus on short-term, visible results}

While such "roving bandits" are probably more the exception than the rule, state officials are nevertheless increasingly concerned about "short-termism" at local levels. China's cadre management system should, in theory, curtail such predatory behaviour and encourage local officials not to neglect environmental issues by assessing their performance against standards set by upper-level authorities. However, recent public commentary suggests that short-termism associated with high cadre turnover is a significant and growing problem for environmental governance in China. The short tenure of leaders, combined with a general preference for costly show projects (which often create rent streams for local officials), leads to short-sighted behaviour and can inhibit the formation of long-term sustainable development plans. As one commentator in a prominent Party journal put it:

[T]here are some cadres who, because they know there is a "when the time comes, they'll move on" guarantee, give weight to “apparent accomplishments" (xianji 显绩) and much less to "potential accomplishments" (qianji 潜绩). They place less emphasis on foundational, longterm, strategic work and pursue short term, false political accomplishments. ${ }^{46}$

As discussed in more detail below, Party and government leaders have recently begun to think of ways to motivate local officials to prioritize "foundational, long-term, strategic work."

Incentives in the cadre evaluation system interact with the typically short time horizons of local leaders and predispose them to select the path of least resistance in implementation of environmental initiatives. By contrast, environmental projects which are not seen to enhance a cadre's chances of promotion and which take a long time to produce results will tend to be ranked at the bottom of the prioritization list. As such, cadres' incentives to secure short-term goals can be at odds with the centre's expansive green growth mandate and many environmental projects that are not realizable in the short term are sidelined. For instance, many leaders have invested significant resources in tree planting in order to meet their annual forest coverage targets in the 11th and 12th Five-Year Plans (FYP), an initiative that produces quick and visible results, but many of them have delayed economic restructuring as it is a difficult and complex process that can take years to bear fruit.

Interviews revealed a number of other negative, unintended consequences of a system in which leading cadres are pressurized to deliver visible and measurable environmental outcomes within their short tenure. For instance, the EPB head in a Shandong county pointed out that the incentive for visible and measurable results can lead to wasteful misallocation of resources:

In order to further reduce chemical oxygen demand in the 12th FYP, our county is planning to build one sewage treatment plant for each town. Personally, I do not think that this is a good idea. It would be better to expand the existing sewage plant and build a better pipe network to collect wastewater rather than build many small plants in each town. This would be less 
expensive. For some towns, it is also not financially feasible for them to build their own treatment plants and their township government will face severe financial burdens in the future. But, this is a political problem. Some leaders think that building a sewage treatment plant for each town sounds better and provides more political accomplishment value. In the short term, the plans sound impressive to their superiors, but the next leaders inherit these financial burdens and have to deal with failures as not every town will be able to complete the constructions. ${ }^{47}$

The short time horizons of cadres can also lead to a cavalier attitude to costs since leaders can expect to be onto their next assignments by the time the bill comes. For instance, aside from the inherent risks of Geng Yanbo's all-in tourism-based strategy, the mayor's successors will inherit huge amounts of municipal debt. Under the pressure of a de facto five-year term limit, Geng launched many initiatives almost immediately upon taking office and project financing has been pieced together in an ad hoc fashion. Enterprise investment has played only a minor role in Datong's transformation so far, with the majority of project financing coming from land sales and bank loans. Typical of his "can't wait" (deng bu $q i$ 等不起) attitude, Geng's response to questions raised about the city's construction projects being plagued by legal violations was: "I do not have time to wait, so demolition cannot wait." 48 Some funding for cultural restoration projects has come from the central and provincial governments, but money for a huge city wall construction project has been drawn exclusively from municipal finances. ${ }^{49}$ The final tab for these projects may total 50 billion yuan, a vast sum considering that Datong municipality's revenue came to only 14 billion yuan in 2010 . Revenue shortfalls have been made up with bank loans, land sales and high ticket prices for the refurbished sites. Geng has, reportedly, begun to run out of credit with local banks and the word in Datong officialdom is that "Geng cannot get a loan” (Geng ban buliao daikuan 耿办不了贷款). Geng's successor will be saddled with the costs of this "big-bang" style of industrial restructuring.

Leaders' short time horizons also create problems for the environmental planning system. An official in Chenzhou 椰州 noted that the short time span given to cadres has forced a change in the allocation of energy intensity targets in local five-year plans:

Owing to political cycles, leaders sometimes select lower energy saving targets at the beginning of a five-year period because they will only stay in the locality for two more years and leave the problem for the next leader. This is also one of the reasons why the emphasis has shifted from five-year targets in the 11th FYP to annual targets in the 12th FYP. ${ }^{50}$

Short office tenures also affect the quality of environmental policy implementation. Many of the environmental targets in the 11th FYP were implemented at the eleventh hour and did not yield lasting change. In some localities, mandatory energy intensity targets were only met at the very end of the planning period

48 Xin Jing bao. 2011. "Shi zhang 'deng bu qi,' ze qiang chai ting buxia” (Mayor will not stop demolitions), 22 May, http://news.xinhuanet.com/comments/2011-05/22/c_121443752.htm. Accessed 4 February 2013.

49 INT34_30092011.

50 INT6_22052012. 
using extreme, and sometimes socially harmful, measures. These included cutting electricity to hospitals, homes and rural villages. Local governments also temporarily shut down energy-intensive companies for a given period of time only to allow the same enterprises to re-open, a method known as "sleeping management" (xiumian guanli 休眠管理). 51 These low-quality implementation approaches ensured that leading cadres met the energy intensity target outlined in their individual responsibility contracts, but effectively put off the difficult matter of how localities can find more long-term energy efficient solutions.

\section{New lords, new laws}

Institutionalized post-shuffling of local leading cadres can result in damaging discontinuity in local sustainable development initiatives. Local officials who are self-maximizing may prefer to gain exclusive credit for successful initiatives rather than share the glory with successors and predecessors. This can result in adverse effects for local green growth when newly-posted cadres indiscriminately stop existing initiatives, regardless of their merits, in order to place their own stamp on a locality in accord with the tradition of "new lords, new laws" (xin guan xin $f a$ 新管新法).

Leadership discontinuity often comes along with policy uncertainties and "policy freezes." For instance, there have been 13 changes of Party secretaries between 2000 and 2010 in Baoding 保定, a municipality in Hebei province, and each leadership change was accompanied by departments in the city taking a "wait and see" approach, "trying to decipher signs from the new leader(s) and determine in which direction the wind will below (feng wang nali chui 风往哪里 吹)." 52 With the installation of every new leader, important environmental policy decisions were put on hold, resulting in transition periods of months or even a year. ${ }^{53}$ As a result, local officials working at the departmental level in Baoding complained that policy meddling from their constantly changing superiors in the city government prevented them from achieving any kind of coherence in their policies. ${ }^{54}$

Baoding is by no means an exception. The case of Datong's maverick mayor described above is also illustrative of the practice of "new lords, new laws." Soon after taking office, Geng let it be known that he would play by different rules. A government official recalls one of Geng's first new measures:

When Geng first arrived in Datong, he called a halt to all the real estate projects that did not meet construction standards. Real estate developers interpreted this as a sign that Geng wanted bribes, but they were wrong. Geng directed his subordinates to take the money they offered him and deposit it in a special government fund used for city construction. ${ }^{55}$

51 Kostka and Hobbs 2012.

52 INT04_11092011; Shin Forthcoming.

53 INT04_11092011.

54 Shin Forthcoming.

55 INT34_30092011. 
This demonstrates that, as outsiders, newly appointed leaders can break with existing patterns and habits. As discussed above, Geng subsequently consolidated the coal industry and initiated a large-scale restructuring programme to develop a non-coal industry based on tourism. While many credit Geng with laying a firm foundation for Datong's industrial transformation, it remains to be seen whether this greening growth strategy is in fact viable and whether the next leader will follow Geng's vision of tourism development or select a different focus.

Leadership changes at the departmental level can be equally disruptive. A high-ranking official in the Datong government described how ongoing projects can be indiscriminately stopped because of the arrival of a new departmental head:

If a leader changes, he or she may have different priorities and stop the work already begun. For example, I worked for a year and half on a project that included a lot of background research and discussion with different partners and it was almost completed ... Then there was a change of leader in the commission who thought this project was not promising and put a stop to it. ${ }^{56}$

Coupled with the focus on short-term results, the tradition of new lords, new laws contributes to a structural bias against faithful implementation of policies with long-term objectives.

\section{Constraint on implementation capacities: limited local knowledge and networks}

Cadre rotation can also impact environmental policy implementation in more prosaic ways. In the space of a three or four-year tenure, circulating officials spend much of their time simply getting up to speed in their new localities. Zhong offers a pointed description of the problem:

It usually takes key county or township/town officials one or two years to settle in, familiarize themselves with the environment and various governmental agencies under their jurisdiction, and establish smooth working relationships with colleagues and subordinates. It probably takes the same amount of time, if not longer, to study and develop a new comprehensive economic development plan for the locale. ${ }^{57}$

In an average tenure period, potentially more than half of a leader's time could be taken up with getting to know the lay of the land and gaining the trust of subordinates. Since cadres only have a small window in which to familiarize themselves with a new area, their implementation capacity might be constrained by limited knowledge of local circumstances. Some officials reported that newcomers sometimes made overblown promises as a result. In Chenzhou, a local cadre complained: "Sometimes, local leaders do not do deep research about their localites. Instead, they set even higher targets compared to the ones received from the upper level in order to impress their superiors. But these targets are not suitable and not realistic for the locality." 58 
The few localities that are exceptions to the rule of rapid leader turnover also illustrate the salience of leaders' time horizons and their effect on cadres' local knowledge and networks. Xiaoyi 孝义 county in northern Shanxi is one such place. Like Datong, Xiaoyi is a resource-based economy with a coal-dependent industrial structure in the midst of transformation. In contrast to Datong's rushed implementation approach to economic transformation, Xiaoyi's greening growth strategy has built up gradually with guidance from a strong and locally-rooted leadership group. Recent Party secretaries in Xiaoyi have served for an average of 8.3 years, and mayors an average 6.2 years, much longer than the average tenure of local leaders. ${ }^{59}$ This high degree of continuity in the local leadership group has helped Xiaoyi's leaders to stay focused on transforming the local economy over the last decade. According to one former deputy mayor, leadership continuity has given local development a stepwise quality:

The worst thing for a local government is frequent change in the leadership group and planning. In Xiaoyi, the mayor will usually become the next Party secretary so the top leaders of the two terms are old partners, meaning there is good continuity. Also, every new period the leaders are doing better. The mayor and Party secretary in the 1990s built roads to connect Xiaoyi with the outside. The next leaders started industrial restructuring. The current Party secretary has placed greater emphasis on equitable growth and environment as well. Each period's achievements serve as inspiration for the next. ${ }^{60}$

This continuity has helped Xiaoyi's leadership group make very effective use of the relationships it has built over time with upper levels of government, and especially with local industry. These precious guanxi resources are effectively preserved over time since long-serving mayors typically become long-serving Party secretaries in Xiaoyi. Consistent leadership helped the city win national awards and secure planning support from upper levels since stability meant followthrough on policy priorities and the absence of "new lords, new laws" problems. For instance, in 2002 the Xiaoyi leadership fixed on the goal of obtaining a central-level experimental city designation (shidian chengshi 试点城市) to aid their economic transformation. Local leaders were first dispatched to learn from experimental cities in the north-east in preparation for their application. After seven years of careful project development and implementation, Xiaoyi was finally named a "Resource-exhausted transformation experimental city" in 2009, one of only 44 nationwide and the only one in Shanxi. This title is not just an accolade for the city's leaders; it has also brought the city 200 million yuan in central government funding. ${ }^{61}$

Xiaoyi's leadership group has also used its guanxi ties to induce local businesses to share the burden of reducing Xiaoyi's economic dependence on coal. Strikingly, local coal enterprises, many of which are privately owned, have actually been given soft targets in local plans for investment in economic

59 Xiaoyi county leaders' tenure times are twice the average of other leading county cadres in the same municipality; Party secretaries in other counties in Lüliang stayed an average of 3.6 years $(\mathrm{N}=28)$ and mayors an average of 3.1 years $(\mathrm{N}=35)$.

60 INT15_21092011.

61 INT11_26092011. 
transformation projects: "Coal production enterprises should each launch noncoal projects of between one and two billion RMB; each coking enterprise should launch projects of one billion RMB or more in non-coal or downstream processing projects." 62 In addition, Xiaoyi leaders have effectively "bundled" coal restructuring with the goal of developing non-coal industries by providing incentives for former coal bosses whose enterprises were eliminated as part of a 2006 industry clean-up to start greener businesses. For instance, with government backing, a former mine owner whose enterprise was closed down brought a Walmart outlet to Xiaoyi and has also set up a new business marketing agricultural products. Leadership continuity likely contributed to the leaders' success in securing investment because investors can be confident that plans will not shift radically with personnel changes in the leadership group.

\section{Discussion and Conclusion}

The evidence gathered in interviews suggests that, while cadre rotation has some benefits for environmental policy implementation, high cadre turnover has generated significant negative and unintended consequences. We find that cadre rotation affects both cadres' incentives and their implementation capacities. In terms of incentives, shuffling cadres around every three to four years keeps officials' feet to the fire, as they are required to report accomplishments regularly to superiors. Yet, as with leaders in Dionne's study of HIV/AIDS policy, Chinese leaders with short time horizons tend to select cheap and quick approaches to environmental policy implementation. All else being equal, they prefer short-term highly visible projects that yield outcomes during their own tenure periods, while long-term, costly and complex initiatives are often sidelined. As mentioned, state leaders are increasingly concerned about short-termism and local leaders themselves see the constraints of this system. For example, Geng Yanbo demanded a five-year term in Datong so that he could make significant changes and receive credit for them. One informant told us: "When Geng was working in Taiyuan as vice-mayor [2006-2008] and he knew he was going to be sent elsewhere, he demanded to be stationed in Datong for at least five years, otherwise he would not want to go. He wanted to make a long-term impact and be a leader with vision." 63

While the effect of frequent rotation on officials' incentive structures is problematic, the implications for cadres' implementation capacity is more mixed. On the one hand, by frequently moving them around departments and regions, cadres can play a role in the dissemination of new ideas and resources. Cadres with previous work experience in SOEs are well-placed to negotiate effectively with managers the implementation of onerous environmental regulations. On the other hand, cadres who come in as outsiders to a new locality lack the 
local knowledge and networks essential for drawing local businesses into greener growth initiatives or for obtaining additional funding from provincial and central governments. When local leaders have attained sufficient understanding of local conditions and interests to serve as effective leaders, it is already time to take up a new post elsewhere.

How might China's policymakers rectify the adverse effects of high cadre turnover highlighted in our interviews? This is a complex question deserving of its own paper; our analysis suggests that national leaders could strive to increase local cadres' time horizons. A step forward in this regard was the central government's 2006 "Interim provisions on the tenure of leading Party and government cadres," ${ }^{64}$ which stipulates that, except in special cases, leading cadres ought to serve out their five-year terms in full. Short-termism associated with "tenure rush” (gan renqi 赶任期) prompted the Guangdong provincial Party committee in 2011 to remind local leaders that "success does not have to be realized in my tenure" (gongcheng bu bi zai wo renqi 功成不必在我任期). ${ }^{65}$ In spite of recent national calls to adhere strictly to the recommended five-year rules, there has not yet been a discernible impact on official tenures at the provincial and municipal level; indeed, the current trend is towards faster turnover of officials.

In all, the considerable perverse effects of local officials' short time horizons give reason to doubt the more optimistic claims about China's version of environmental authoritarianism. The purported authoritarian advantage is that, in comparison to their counterparts in democratic systems, eco-elites enjoy greater freedom of action owing to their relative autonomy from interest groups and secure positions in power. Our analysis suggests that behaviour linked to leaders' short time horizons serves to undermine any such potential advantage. Local leaders under pressure to produce "political achievements" in a few short years tend to select the path of least resistance in selecting quick, low-quality approaches to implementing environmental policies and, while nominally following national directives, are actually putting off the difficult business of creating a sustainable growth path.

\section{References}

Beeson, Mark. 2010. "The coming of environmental authoritarianism.” Environmental Politics 19(2), 276-294.

Cai, Yongshun. 2004. "Irresponsible state: local cadres and image-building in China." Journal of Communist Studies and Transition Politics 20(4), 20-41.

Dionne, Kim Yi. 2011. "The role of executive time horizons in state responses to AIDS in Africa." Comparative Political Studies 44(1), 55-77.

64 Communist Party of China Central Committee. 2006. "Dangzheng lingdao ganbu zhiwu renqi zanxing guiding."

65 People's Daily Online. 2011. "Meiti pi zhengji gongcheng 'gan renqi”” (Media criticize political accomplishment projects 'tenure rush'), 15 July, http://news.xinhuanet.com/politics/2011-07/15/c_121671897. htm. Accessed 4 February 2013. 
Edin, Maria. 2003. "State capacity and local agent control in China: CCP cadre management from a township perspective." The China Quarterly 173, 35-52.

Gilley, Bruce. 2012. "Authoritarian environmentalism and China's response to climate change." Environmental Politics 21(2), 287-307.

Heilmann, Sebastian. 2008. "From local experiments to national policy: the origins of China's distinctive policy process." The China Journal 59, 1-30.

Huang, Yasheng. 1996. Inflation and Investment Controls in China - The Political Economy of Central-Local Relations during the Reform Era. New York: Cambridge University Press.

Huang, Yasheng. 2002. "Managing Chinese bureaucrats: an institutional economics perspective." Political Studies 50, 61-79.

Josephson, Paul R. 2004. Resources under Regimes: Technology, Environment, and the State. Cambridge, MA: Harvard University Press.

Kostka, Genia. 2013. "Environmental protection bureau leadership at the provincial level in China: examining diverging career backgrounds and appointment patterns." Journal of Environmental Policy and Planning 15(1), 41-63.

Kostka, Genia, and William Hobbs. 2012. "Local energy efficiency policy implementation in China: bridging the gap between national priorities and local interests." The China Quarterly 211, 765785.

Landry, Pierre. 2008. Decentralized Authoritarianism in China: The Communist Party's Control of Local Elites in the Post-Mao Era. New York: Cambridge University Press.

Lester, James P., and Ann O.M. Bowman. 1989. "Implementing environmental policy in a federal system: a test of the Sabatier-Mazmanian model." Polity 21(4), 731-753.

Matland, Richard E. 1995. "Synthesizing the implementation literature: the ambiguity-conflict model of policy implementation." Journal of Public Administration Research and Theory 5(2), 145-174.

Mei, Ciqi. 2009. "Bringing the Politics Back In: Political Incentives and Policy Distortion in China." $\mathrm{PhD}$ diss., University of Maryland.

O’Brien, Kelvin J., and Lianjiang Li. 1999. "Selective policy implementation in rural China." Comparative Politics 31(2), 167-186.

Olson, Mancur. 1993. "Dictatorship, democracy, and development." American Political Science Review 87(3), 567-576.

Sabatier, Paul, and Daniel Mazmanian. 1980. "The implementation of public policy: a framework of analysis." Policy Studies Journal 8(4), 538-560.

Seckington, Ian. 2007. "County leadership in China: a baseline survey." Nottingham China Policy Institute, Discussion Paper 17.

Shearman, David J.C., and Joseph Wayne Smith. 2007. The Climate Change Challenge and the Failure of Democracy. Westport, CT: Praeger.

Shin, Kyoung. Forthcoming. "The City and the Agency: A Study of the Rise and Fall of Low-Carbon City in Baoding, China, 1992-2011.” PhD diss., Massachusetts Institute of Technology.

Wright, Joseph. 2008. "To invest or insure? How authoritarian time horizons impact foreign aid effectiveness." Comparative Political Studies 41(7), 971-1000.

Yi, Fan. 2007. "Ganbu jiaoliu fumian yingxiang jiqi kongzhi" (The adverse effects of the cadre rotations system and how to control them), Zhongguo dang zheng ganbu lun tan, 9 March, http://theory. people.com.cn/GB/49150/49152/5456856.html. Accessed 4 February 2013.

Zhong, Yang. 2003. Local Government and Politics in China-Challenges from Below. Armonk, NY: M.E. Sharpe. 